\title{
Clinical Profile and Prescribing Pattern of Cirrhosis in a Tertiary Care Hospital
}

\author{
Meenu Vijayan*, Anisha K A, Arjun Sanal Kumar Selina and Roshni P R \\ Department of Pharmacy Practice, Amrita School of Pharmacy, Amrita Vishwa Vidyapeetham University, Health Sciences Campus, \\ AIMS, Ponekkara.P.O, Kochi-682041, Kerala, India.
}

\begin{abstract}
Liver cirrhosis is one of the major non communicable diseases, which is expected to be a prime health care concern of the $21^{\text {st }}$ century. In the present world, the number of persons suffering from the liver disorders is increasing. This may be due to the change in lifestyle and many stress related factors. Identification of the demography of patients with cirrhosis is of great importance in the current health care scenario for the calculation of prevalence of this frustrating disease. The aim of the study was to observe the clinical profile and treatment pattern in cirrhotic patients. This was an observational prospective study carried out in in-patient department of Gastroenterology, Amrita Institute of Medical Sciences for a period of 8 months. 150 patients diagnosed with liver cirrhosis and who satisfied the inclusion criteria were included. Specially designed standardized data collection form was used. From this study, we identified that the majority of the patients were male who belonged to the age group 51-60 years and majority of them were from urban area. Positive family history was noted in few patients. Abdominal pain was the most frequent symptom seen in majority of the cirrhotic patients. Most of the patients belonged to the Child Pugh Class C category. Antibiotics were the most commonly prescribed category of drug. Among this, cephalosporins were the most frequently used drug.
\end{abstract}

Keywords: Cirrhosis, Clinical profile, Prescribing Pattern, Demographics.

\section{INTRODUCTION}

Cirrhosis is a severe, chronic, irreversible and non-communicable disease, which is characterized by histological development of regenerative nodules surrounded by fibrous bands in response to chronic liver injury. The natural history of cirrhosis is dependent on both the etiology and treatment of the underlying cause. The exact prevalence of cirrhosis is unknown. A large proportion of cirrhosis patients only come into clinical attention until complications arise and previously undiagnosed cirrhosis is still frequently found at autopsy. It can be primarily divided into two; compensated cirrhosis and decompensated cirrhosis. Initial clinical presentation of patients with decompensated cirrhosis is still common and is characterized by the presence of dramatic and life-threatening complications, such as haemorrhage, ascites, spontaneous bacterial peritonitis, or hepatic encephalopathy ${ }^{1}$. The treatment also depends upon the existing co morbidities.This gave us the idea to generate our study. The general laboratory signs that are frequently elevated in cirrhosis are AST, ALT, ALP and OGT. The general clinical features of cirrhosis include jaundice, nodular liver and spider angionitis. ${ }^{2}$ Ultrasonography, Helical CT and MRI, Fibro scan are the imaging techniques available now to identify the structural modifications of liver. The main pre disposing
Submitted Date : 01-09-2014 Accepted Date : 05-09-2014

DOI: 10.5530/ijopp.7.3.12

Address for correspondence:

Dr. Meenu Vijayan

Department of Pharmacy Practice, Amrita School of Pharmacy, Amrita Vishwa Vidyapeetham University, Health Sciences Campus, AIMS, Ponekkara.P.O, Kochi-682041, Kerala, India.

E-mail id: meenuvijayan@ aims.amrita.edu

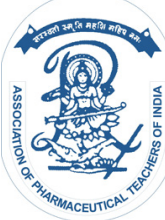

www.ijopp.org 
factors leading to cirrhosis include viral infections, alcohol, primary biliary, genetic, autoimmune, etc. and the complications mainly found are portal hypertension, variceal bleeding, hepatic encephalopathy, ascites, spontaneous bacterial peritonitis, etc. ${ }^{3}$

Identification of prescribing pattern enabled us to determine the most used drug in cirrhosis; which helps to identify the better treatment regimen for treatment. The purpose of study was to identify the clinical profile and prescribing pattern associated with cirrhosis and thus to decrease the circumstances of becoming a cirrhosis patient and to minimize the risk to develop complications. The symptoms observed helped to decide the nature of disease and the identification of class determined the severity. Family history helped us to identify the effect of genetic factors in cirrhosis. Identification of area of residence of patient helped in evaluating the life style factors leading to cirrhosis.

\section{METHODOLOGY}

\section{Design of Study}

Non-experimental (Observational), prospective and cross sectional study.

\section{Settings}

The study was done in the department of Gastroenterology, Amrita Institute of Medical Sciences(a tertiary care referral and teaching hospital, in Kochi, Kerala located in an urban area that captures patients from all settings: (Rural through Urban).The hospital established in 1998, is approved by the Medical Council of India for conducting graduate and post graduate course in medicine. The Gastroenterology department is the only full-fledged Gastroenterology centre in the entire state of Kerala and provides advanced care for cirrhosis as well as complex hepatic diseases. There are complete facilities for the investigation and treatment of gastroenterological problems in adult, pediatric and geriatric patients and all complication of cirrhosis.

\section{Study Population}

Patients visiting the inpatient department of Gastroenterology and who satisfy the inclusion criteria.

\section{Sample Size}

$n=150$

\section{Inclusion Criteria}

- Patients under all age groups.

- Patients diagnosed to have cirrhosis.

- Patients willing to participate in the study.
- Patients visiting inpatient department of Gastroenterology.

\section{Exclusion criteria}

- Patients unwilling to co-operate.

- Patients visiting outpatient department of Gastroenterology.

\section{Method of Selection}

Patients were selected on the basis of inclusion and exclusion criteria.

\section{Data Collection}

- Examination of Patient medical record directly.

- Examination of Patient medical record using AHIS (Amrita Hospital Information System).

\section{Tools of Collection}

Patient data collection form

\section{Duration of Study}

Data collection was carried out for a period of 8 months from $1^{\text {st }}$ July 2013 to $28^{\text {th }}$ February 2014.

\section{MATERIALS AND METHODS}

A non-experimental (observational), prospective study was carried out on patients with cirrhosis at the Gastroenterology inpatient department of AIMS, KOCHI. A standardised data collection form was prepared and necessary data was collected from the patient files. The data collection form provided demographic details of the patients which included age, sex and location of the patients. Additional information including predisposing factors and complications were also noted. Individual analysis of patient record was carried out to minimise errors. Microsoft Excel was used in statistical analysis.

\section{RESULTS}

In the present study, the majority of the patients (34\%) belonged to the age group of 51-60 years, followed by the age group of $41-50$ years $(26 \%)$ (Table 1) Only $2.67 \%$ of the patients were in the age groups of $21-30$ years and $2 \%$ for $71-80$ years. None of the patients were above 80 years and below 20 years. The youngest patient was 23 years old and oldest 74 years and the male to female ratio were 20:1 (Figure 1). It also showed that $(57.33 \%)$ of the patients were from urban area and the remaining (42.67\%) from rural area (Table 2). Only $14.67 \%$ of the patients had a family history of cirrhosis and in majority of patients there was no history of cirrhosis in the family (Figure 2). Majority $(29.67 \%$ ) of the 
patients had abdominal pain + edema + vomiting and only $6.67 \%$ of the patients had abdominal pain alone as symptom. Abdominal pain was the most seen symptom in cirrhosis (Table 3). 50\% of population were in category $\mathrm{C}$ followed by $35 \%$ in $\mathrm{B}$ and $11 \%$ in A (Figure
$3)$. The most prescribed drugs for cirrhosis are vitamins (98.66\%), antibiotics (99.33\%) and chologogues $(92.66 \%)$ while anti- depressant drugs and anxiolytics $(.66 \%$ ) (Figure 4). Among antibiotics, cephalosporins holded the foremost share (Table 4).

\begin{tabular}{|c|c|c|c|c|c|c|}
\hline \multirow{2}{*}{$\begin{array}{c}\text { Age } \\
\text { (Years) }\end{array}$} & \multicolumn{2}{|c|}{ Males } & \multicolumn{2}{|c|}{ Females } & \multirow{2}{*}{$\begin{array}{c}\text { Total } \\
\text { Number }\end{array}$} & \multirow{2}{*}{ Total Percentage } \\
\hline & Number & Percentage & Number & Percentage & & \\
\hline $1-10$ & 0 & 0 & 0 & 0 & 0 & 0 \\
\hline $11-20$ & 0 & 0 & 0 & 0 & 0 & 0 \\
\hline $21-30$ & 4 & 2.79 & 0 & 0 & 4 & 2.67 \\
\hline $31-40$ & 15 & 10.49 & 1 & 14.29 & 16 & 10.67 \\
\hline $41-50$ & 39 & 27.27 & 0 & 0 & 39 & 26 \\
\hline $51-60$ & 47 & 32.87 & 4 & 57.14 & 51 & 34 \\
\hline $61-70$ & 35 & 24.48 & 2 & 28.57 & 37 & 24.67 \\
\hline $71-80$ & 3 & 2.09 & 0 & 0 & 3 & 2 \\
\hline$>80$ & 0 & 0 & 0 & 0 & 0 & 0 \\
\hline Total & 143 & 100 & 7 & 100 & 150 & 100 \\
\hline
\end{tabular}

Table 2: Area of Residence of Cirrhosis Patients $(n=150)$

\begin{tabular}{ccc} 
Area of Residence & Number of Patients & Percentage of Patients \\
\hline Rural & 64 & 42.67 \\
Urban & 86 & 57.33 \\
\hline Total & 150 & 100 \\
\hline
\end{tabular}

Table 3: Symptoms Associated with Cirrhosis ( $n=150)$

\begin{tabular}{ccc} 
Symptoms & Number of Patients & Percentage of Patients \\
\hline Abdominal Pain & 10 & 6.67 \\
Bleeding & 11 & 7.33 \\
Bleeding + Edema & 37 & 24.67 \\
Abdominal Pain+Edema+Vomiting & 44 & 29.33 \\
Abdominal Pain+Fever+Vomiting & 19 & 12.67 \\
Edema+Fever+Altered Sensorium & 29 & 19.33 \\
\hline Total & $\mathbf{1 5 0}$ & $\mathbf{1 0 0}$ \\
\hline
\end{tabular}


Table 4: Antibiotics Used in Liver Cirrhosis Patients $(n=150)$

\begin{tabular}{ccc} 
Antibotic Class & Number of Patients & Percentage of Patients \\
\hline Cephalosporins & B- LACTAMS & \\
Penicillin & 67 & 44.96 \\
Carbapenems & 2 & 1.34 \\
Rifamycin & 2 & 31.54 \\
Fluroquinolones & 47 & 20.80
\end{tabular}

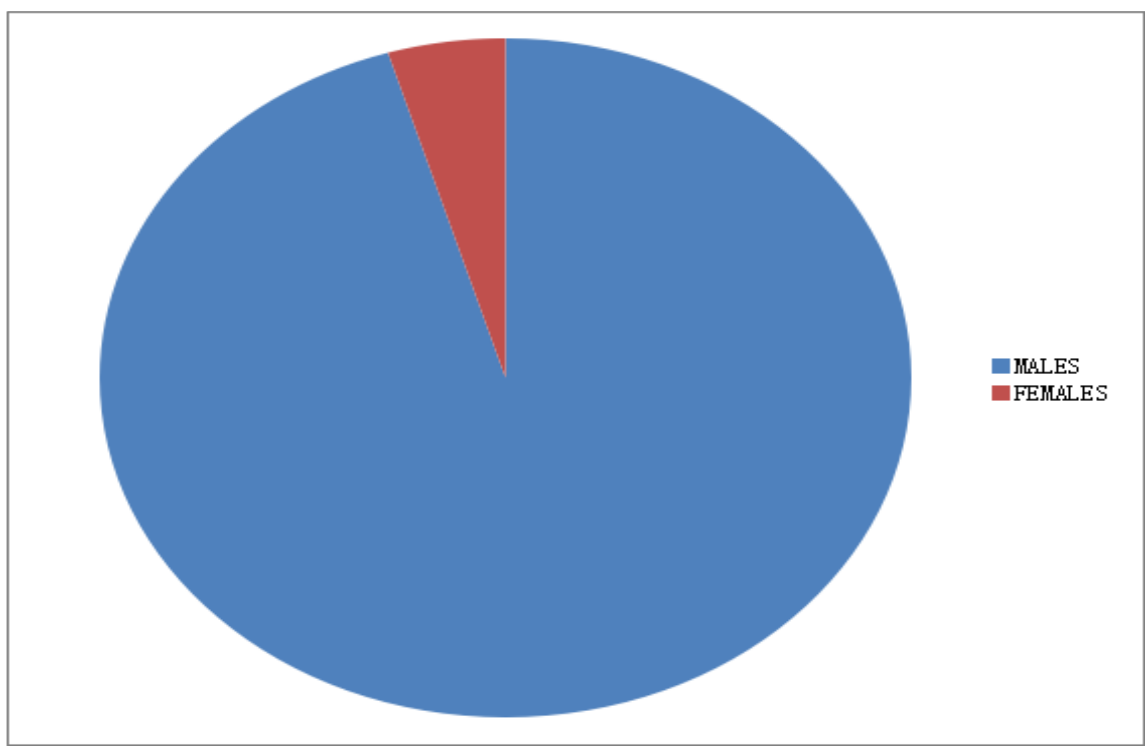

Figure 1: Gender Distribution of Patients with CIRRHOSIS $(n=150)$

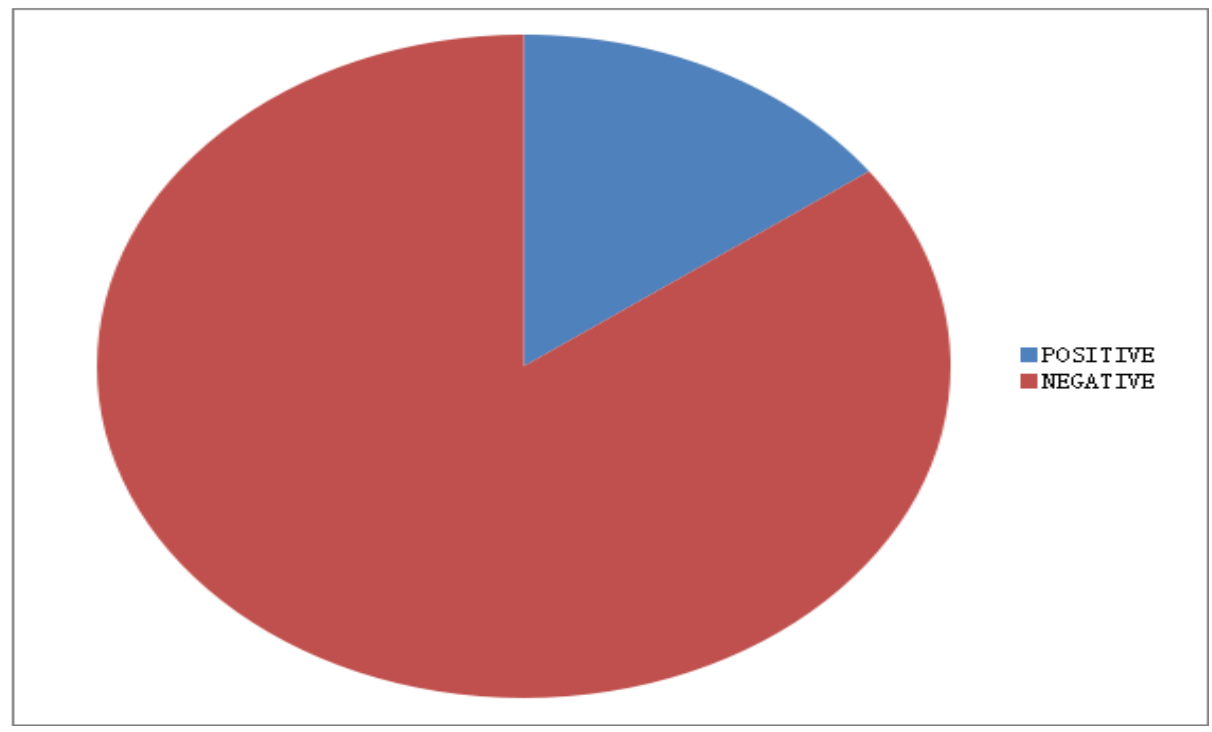

Figure 2: Family History of Cirrhosis in the Sample Population $(n=150)$ 


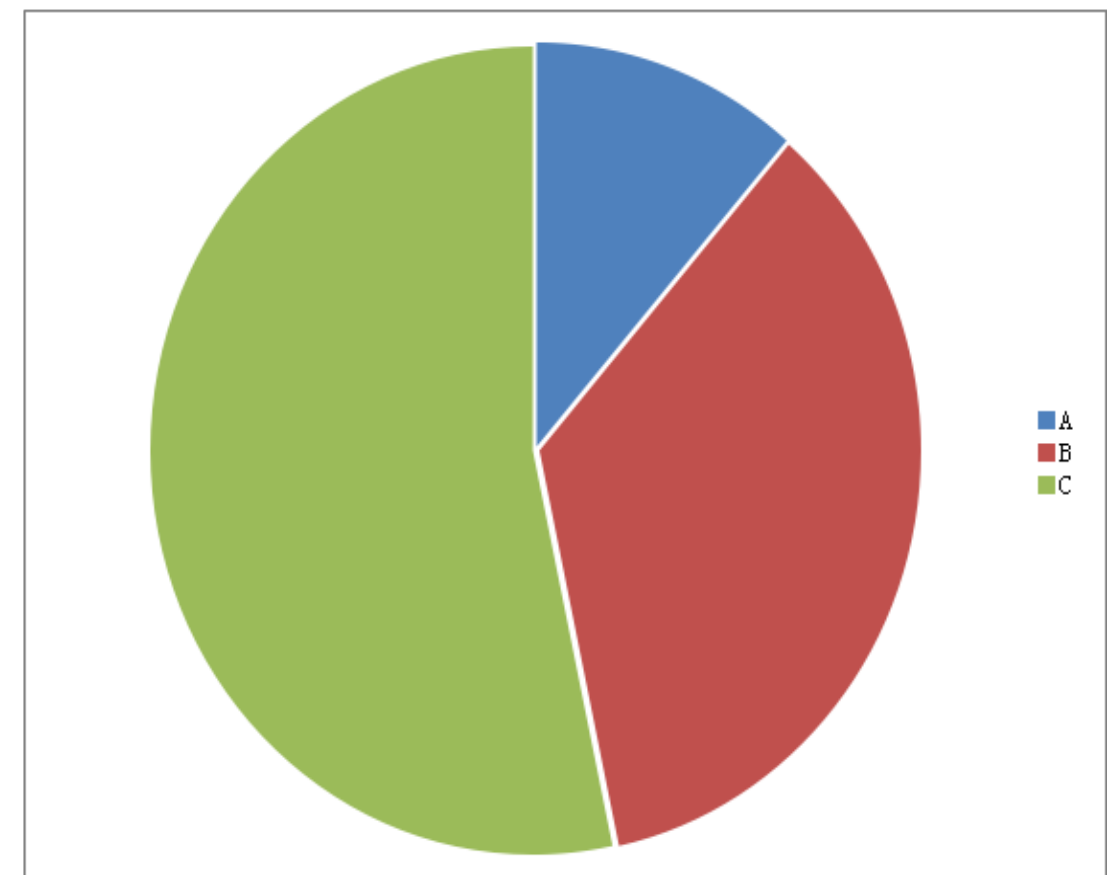

Figure 3: Frequency of Category of Cirrhosis as Per Child PughClass $(n=150)$

\section{PERCENTAGE OF PATIENTS}

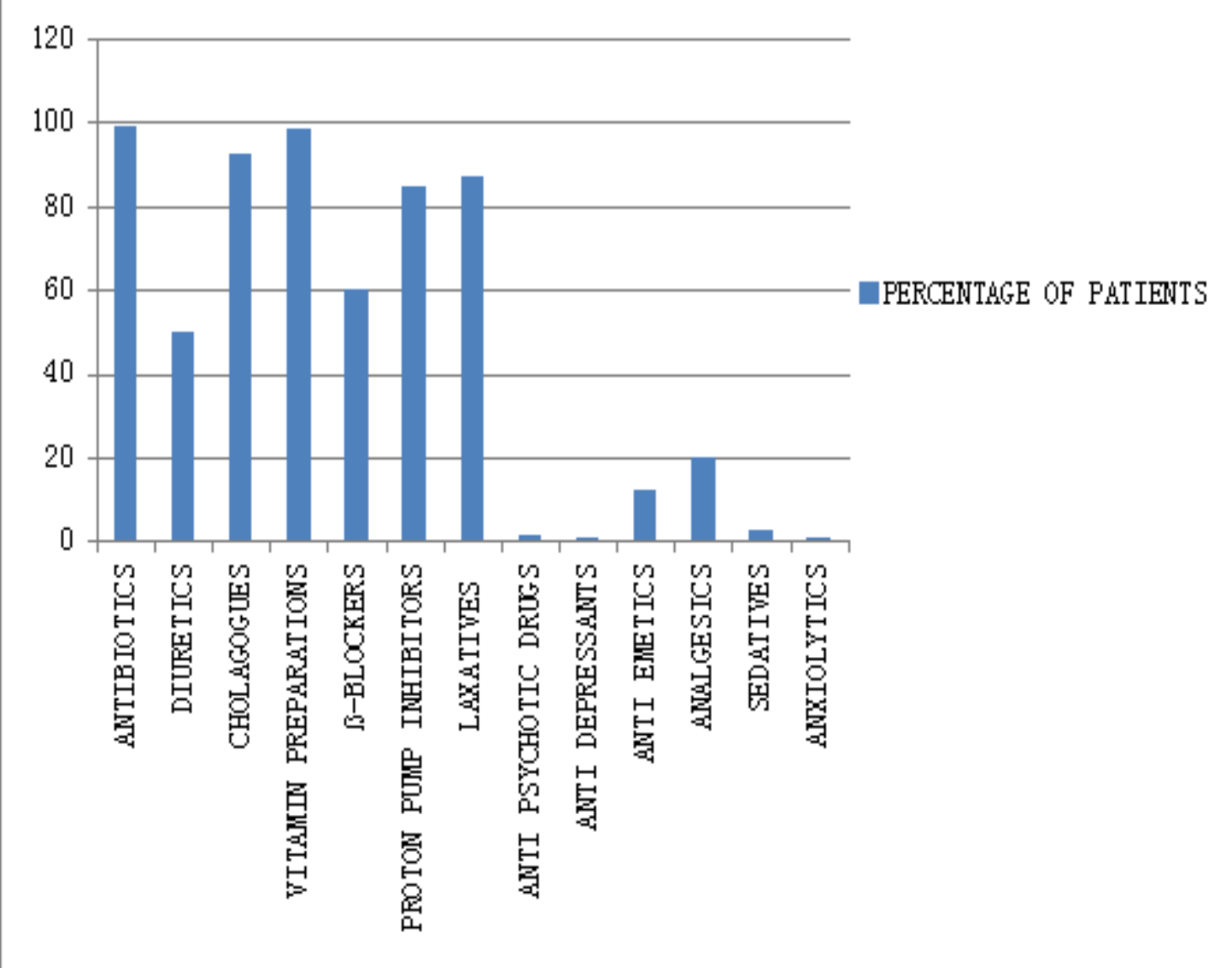

Figure 4: Prescribing Pattern in Cirrhotic Patients $(n=150)$ 


\section{DISCUSSION}

In the total of 150 cases of cirrhosis taken, the majority of the patients were male who belonged to the age group 51-60 years. In a retrospective study, the risk for bacterial endocarditis in cirrhotic patients: a population based 3 year follow up study by Tsung-Hsing Hung, YuHis Hsien et $\mathrm{al}^{4}$ showed $71.1 \%$ males and 28.9 females. It also showed that most patients are in the age group between 60-74years (34.7\%).

Our study showed that $(57.33 \%)$ of the patients were from urban area and the remaining (42.67\%) from rural area. In the retrospective study conducted by Rongey C, Huishen, Hamiton N et al, $30 \%$ patients live in rural or highly rural areas. The change in lifestyle and stress factor is the most reliable reason for the result. Positive family history was noted in few patients.

Abdominal pain was the most frequent symptom seen in majority of the cirrhotic patients.In the study conducted by Kalaitzakis E, Simren M, Olsson R, et al, ${ }^{6}$ cirrhosis show increased severity of gastrointestinal symptoms, which are associated with recent weight loss and impaired health-related Quality of Life. In the prospective study, Factors Associated With Poor HealthRelated Quality of Life of Patients With Cirrhosis by Marchesini G, Bianchi G et al. ${ }^{7}$ Showed 38\% patients each in both Pugh class A and Pugh class B; 24\% in Pugh class C; whereas our study showed most of the patients belonged to the Child Pugh Class $\mathrm{C}$ category. This may be of factor that our study site belonged to a tertiary care hospital and the most patients were referred cases.In medicine (Gastroenterology), the Child-Pugh score ) is used to assess the prognosis of chronic liver disease, mainly cirrhosis. The scores are classified into 3 grades $\mathrm{A}, \mathrm{B}$, and $\mathrm{C}$, indicating Grade $\mathrm{A}$ (well compensated disease) Grade B (disease with significant functional compromise) and Grade $\mathrm{C}$ (decompensated liver disease).

Antibiotics were the most commonly prescribed category of drug. Among this, cephalosporins were the most frequently used drug in our subjects. But in the retrospective study conducted by $\mathrm{K}$ Soares-Weiser, $\mathrm{M}$ Brezis, L Leibovici. ${ }^{8}$ Aminoglycoside (gentamicin or tobramycin) and a beta-lactam (ampicillin or cephalotin) was the most frequently used treatment.

The major weaknesses of our study were that we were not able to interact with the patients directly and we have to rely upon their patient medication records as an ultimate source. But we had the strengths such as we were able to double check the data available easily by using the records and AIMS HIS and thus to minimize errors.

\section{CONCLUSIONS}

Males are most prone to cirrhosis than females at an age group of $51-60$ years. This may be mainly due to the increased alcohol consumption, which is one of the most important predisposing factors for cirrhosis by men in Indian scenario. Since the urban life is a burden, stress factor and lifestyle changes are highly variable and as a result, more number of cirrhosis patients are seen in this area. Abdominal pain was found as the most common symptom among liver cirrhosis patients and child Pugh class $\mathrm{C}$ was the most seen severity class. Antibiotics were the most commonly used class of drug in order to minimize the chances for spontaneous bacterial peritonitis and other complications; even though it seemed a bit irrational which leads to bacterial resistance. Among antibiotics, cephalosporins were best chosen category in our study.

\section{CONFLICTS OF INTEREST}

Nil

\section{REFERENCES}

1. Bosch J, Garcia-Pagan JC. Prevention of varicealrebleeding. Lancet. 2003;361(9361): 952-4.

2. Foutch PG, Sullivan JA, Gaines JA, Sanowski RA. Cutaneous vascular spiders in cirrhotic patients: correlation with hemorrhage from esophagealvarices. Am J Gastroenterol. 1988;83(7):723-6.

3. Roger Walker, Cate Whittlesea. Textbook of Clinical Pharmacy and Therapeutics: Liver Disease. $5^{\text {th }}$ Edition. Churchill Livingstone Elsevier; 2012. 238-54.

4. Tsung-Hsing Hung, Yu-His Hsien, et al. The risk for bacterial endocarditis in cirrhotic patients: a population based 3 year follow up study. International journal of infectious diseases. 2013;17(6): e391-3.

5. Rongey $\mathrm{C}$, Huishen, Hamiton $\mathrm{N}$, etal.Impact of rural residence and health system structure on quality of liver care. Plos one.2013 Dec; 8(12):565-78.

6. Kalaitzakis E, Simren M, Olsson R, etal.Gastrointesinal problems in patients with liver cirrhosis: associations with nutritional status and health related quality of life. Scand J Gastroenterol. 2006 Dec; 41(12): 1464-72.

7. Marchesini G, Bianchi G, Amodio P, Francesco Salerno, et al. Factors associated with poor health-related quality of life of patients with cirrhosis. Gastroenterol.2001; 120(1): 170-8.

8. Soares-Weiser K, Brezis M, Leibovici L. Antibiotics for spontaneous bacterial peritonitis in cirrhotics. Hepatol. 2003; 38(1): 258-66. 